\title{
Em Sintonia no DiscordMe
}

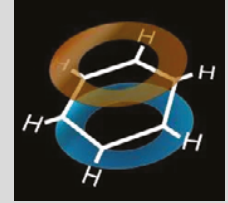

O DiscordMe é uma plataforma virtual que agrega diferentes comunidades, usando um serviço de comunicação por voz, vídeo e texto, o qual é usado por mais de 100 milhões de pessoas. A área das ciências está representada por inúmeros tópicos, tais como a física, a matemática, a astronomia, a biologia e a informática. $\mathrm{Na}$ área da química existem ainda várias secções, das quais destacamos a química orgânica. Aqui movimenta-se uma comunidade muito ativa e diversa, incluindo estudantes e investigadores. Os painéis de discussão abordam temas conexos tais como a química medicinal, a síntese total, técnicas de laboratório, espectroscopia e mecanismos das reações químicas. Em novembro de 2021 existiam 1700 membros inscritos no grupo de química orgânica. Para entrar nesta comunidade é necessário fazer um registo, e depois é só navegar e descobrir um mundo novo.

Veja mais em discord.me/organicchemistry.

$>$

\section{Vasco Bonifácio}

vasco.bonifacio@tecnico.ulisboa.pt
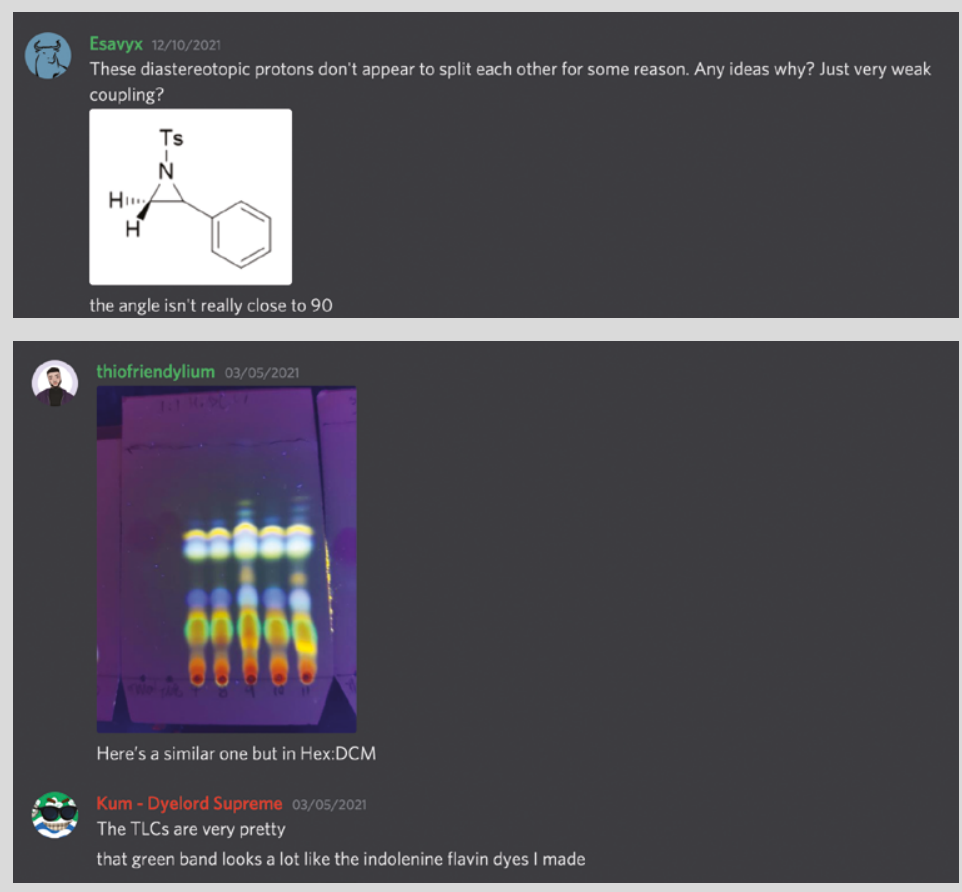

Exemplos de posts no grupo de química orgânica @DiscordMe.

\section{Reddit para a Química?}

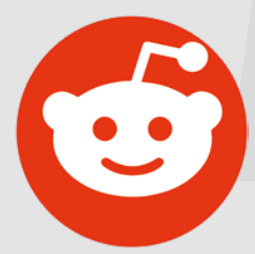

Fundado em 2005 por Steve Huffman, Alexis Ohanian e Aaron Swartz, o Reddit é o 19. ${ }^{\circ}$ website mais visitado no mundo e o $7 . .^{\circ}$ mais visitado nos EUA (em setembro de 2021). Na comunidade Reddit são abordadas as mais diversas temáticas, e claro a química não poderia ficar de fora. 0 subreddit da química ( $r /$ chemistry) conta com cerca de 1500 membros. A temática dos posts é aleatória, pelo que encontramos de tudo um pouco. Para questões mais técnicas foi criado o r/Chempros, um subreddit destinado a químicos profissionais e que já reúne 4000 membros. Para descontrair, também pode aderir ao r/chemistrymemes ou ao r/chemistryjokes porque a química também pode (e deve) ser divertida!

\section{Veja mais em reddit.com/r/chemistry.}

Exemplo de um post @r/Chempros.

Posted by u/SynthesisWorkshop 15 days ago

28 Electrochemical Synthesis of Aziridines - This Week on Synthesis Workshop!

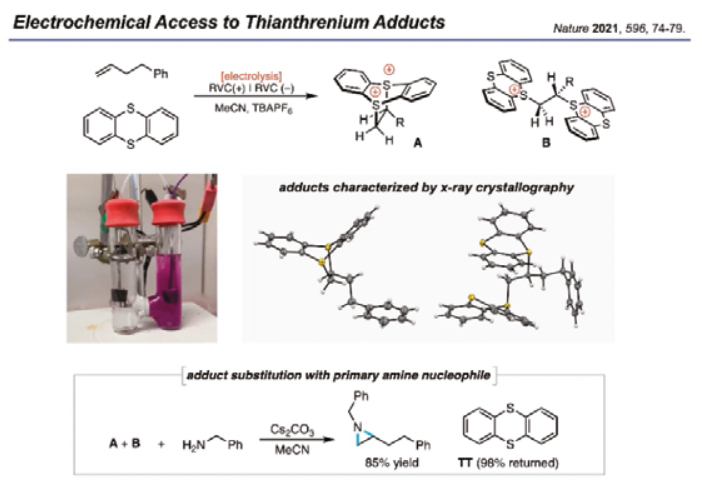

\section{Vasco Bonifácio}

vasco.bonifacio@tecnico.ulisboa.pt

$\square$ 3 Comments + Award $\gg$ share $\square$ Save 